\title{
A Study on Exhibition Evaluation System from the Perspective of Exhibitor
}

\author{
Simin Huang, Yingtao Yang, Yanan Zhou, Peng Ju* \\ Shenzhen Tourism College of Jinan University, Shenzhen, China \\ Email: ^jjppsszz@163.com
}

How to cite this paper: Huang, S. M. Yang, Y. T., Zhou, Y. N., \& Ju, P. (2020). A Study on Exhibition Evaluation System from the Perspective of Exhibitor. Journal of Service Science and Management, 13, 420-434.

https://doi.org/10.4236/jssm.2020.132028

Received: March 29, 2020

Accepted: April 26, 2020

Published: April 29, 2020

Copyright $\odot 2020$ by author(s) and Scientific Research Publishing Inc. This work is licensed under the Creative Commons Attribution International License (CC BY 4.0).

http://creativecommons.org/licenses/by/4.0/

\begin{abstract}
With the rapid development of China's convention and exhibition industry, exhibitions have become more and more in numbers but with uneven qualities and lack of industry norms and evaluation standards. The study of the exhibition evaluation system is conducive to the sustainable development of the exhibition industry. In this study, the indexes and weight degrees of exhibition evaluation from exhibitors' perspectives are explored. Through the literature review of exhibitors and exhibition evaluation, and in-depth interviews with relevant enterprise personnel and experts, the indexes of exhibitors' exhibition evaluation are determined and the exhibition evaluation system is constructed. After the data processing and analysis of the questionnaires, an empirical study on the important factors of exhibitors' exhibition evaluation is conducted, aiming to provide important enlightenment for exhibitors to improve exhibitions' qualities.
\end{abstract}

\section{Keywords}

Exhibitors, Exhibition, Evaluation System

\section{Literature Review}

\subsection{Exhibitors}

Chinese scholars' research on exhibitors is mainly about exhibitors' satisfaction, exhibitors' behavior decision, etc. With the literature searching on CNKI, there are only 26 dissertations aiming to studying on exhibitors, of which only 12 in the past five years; about 60 periodical articles aiming to studying on exhibitors, with the research subjects of exhibitors' satisfaction and exhibitors' behavior decision as those of dissertations.

In Lu Shizhi's (2011) research, the results showed that exhibitors pay more attention to exhibition quality, brand and other factors that can bring tangible 
benefits, and they pay less attention to exhibition service, relationship and cost. In Wang Ya's (2018) research, the results showed that exhibitors' perceived service qualities of conditions of exhibition halls, trade atmosphere and management services all have significantly positive impacts on satisfaction, while their perceived service quality of "supporting services" has no significant impact on exhibitors' satisfaction. Xu Yakun (2012) summarized the influential factors of exhibitors' choices of exhibition into eight factors: past experience, exhibition's influence, external environment, exhibitor's condition, exhibition's service, visitors' influence, planning and organization and exhibition cost. The performance evaluation model of exhibitors constructed by Wang Hanxi (2012) realized to evaluate the performance of exhibitors at six levels: economic benefit effect, display effect and relationship cultivation effect, existing business and brand promotion effect, new business development effect and internal organization efficiency, public promotion effect and industry information acquisition effect.

Different from Chinese scholars' research on exhibitors, scholars from other countries focus their studies more on exhibitors' motivation and decision-making, exhibitors' resource investment, exhibitors' cost and performance evaluation, exhibitors' loyalty, etc.

Kim (2009) divided 44 exhibition services into 9 dimensions: consumer service, hardware facilities, instructions and amenities, exhibition items, relevance, security, public relation, exhibition cost. Carman (1968) stated that, when assessing whether exhibitors should continue to participate in an exhibition or not, they need to consider the exhibition costs of venue rental cost, exhibition area design cost, exhibition area construction cost, logistics and transportation cost, labor cost and customer cost. Godar \& O'Connor (2001) divided the investments of exhibitors into three types: human resources investment, exhibition area design and planning investment, and promotion activities investment. Among literature from other countries, the important factors for exhibitors of choosing exhibitions can be concluded with the quantity and quality of visitors, on-site arrangement of the exhibition hall, service guarantee of the exhibition and cost budget of the exhibitors.

\subsection{Exhibition Evaluation}

Chinese scholars' research on evaluation of convention and exhibition is mainly about the evaluation index systems, which can be divided into evaluation index system of city's convention and exhibition, evaluation index system of exhibition and standard system framework of convention and exhibition industry.

Lei Chun (2018) divided the evaluation indexes into exhibition service indexes and exhibition scale indexes, and then used the analytic hierarchy process to calculate the weights of exhibition evaluation indexes from the perspectives of visitors and of exhibitors. The results showed that exhibitors pay more attention to exhibition promotion efforts and exhibition net area of exhibition scale indexes, and to traffic convenience and safety of exhibition halls of exhibition service indexes. Ling Li and Wang Xiaomin (2016) summarized the exhibition ser- 
vices into four dimensions: "core interest", "basic service", "brand and image" and "core service". They found that exhibitors' exhibition evaluation is a trade-off between "place dependence" and "place identity", while "communication with other exhibitors" is an important factor of exhibitors' repeated participation. Wang Xiaomin (2017) studied the services organizers provided to the exhibitors, and constructed a new service quality evaluation model based on the service core logic and the view that the exhibitors are the creators of service value. The evaluation indexes of the model were selected from three dimensions: physical environment, professional service and core interest. Yang Fangping and Yu Mingyang (2010) constructed the evaluation indexes of the brand exhibition from the perspective of the whole industry, including the recognition and influence of the exhibition, exhibition products and exhibition supporting service. The results showed that the three most important factors of brand exhibition are exhibitors' satisfaction, visitors' satisfaction and the subject of exhibition (Yang \& $\mathrm{Yu}, 2010)$.

James M. Carman (1968) evaluated the exhibition from exhibition performance and exhibition cost. The measurement of exhibition performance included exhibition attractiveness, visitors' purchasing power, potential customer groups and the traffic of exhibition location, and exhibition costs included space cost, exhibition construction cost, design cost, logistics transportation cost and labor cost. On the other hand, Cavanaugh (1976) stated that evaluation indexes of exhibition performance include numbers of visitors, visiting cost, transaction intention and transaction intention cost. Hansen (2004) constructed a broader exhibition benefit evaluation system from comprehensive factors of sales behavior, information collection behavior, image promotion behavior, relationship building behavior, employee incentive behavior, et al, and verified the reliability and effectiveness of the model by an empirical study.

\section{Research Design}

In this study, the main factors and evaluation system are determined within four steps: determining evaluation factors, constructing evaluation index system, analyzing factors of questionnaire indexes and determining evaluation system.

\subsection{Research on Factors of Exhibition Evaluation}

The index factors of exhibition evaluation in this study are obtained by the methods of literature review and analysis, exhibitors' enterprise interviews and expert interviews. In results of literature analysis and expert interviews, there are the same index factors such as exhibition quality and brand, exhibition service, exhibition cost, visitors, exhibition revenue, etc. (Table 1).

A total of 7 enterprise's exhibitors were interviewed of the fields of LED display screen, software programming, teaching equipment, medical beauty, VR, Maker educational products and robot industry within 8 to 15 minutes for each one. Among seven enterprises, 2 enterprises had only one exhibition experience, 
Table 1. Index factors of exhibition evaluation system from literature review ${ }^{\star}$.

\begin{tabular}{|c|c|}
\hline Scholars & Index factors \\
\hline Lu Shizhi (2011) & $\begin{array}{l}\text { exhibition quality and brand; host city; } \\
\text { conditions of exhibition area; relationship with } \\
\text { exhibitor; exhibition service; exhibition cost. }\end{array}$ \\
\hline Wang Ya (2018) & $\begin{array}{l}\text { conditions of exhibition halls; supporting service; } \\
\text { management service; trade atmosphere. }\end{array}$ \\
\hline Xu Yakun (2012) & $\begin{array}{l}\text { past experience; exhibition's influence; } \\
\text { external environment; exhibitor's } \\
\text { condition; exhibition's service; visitors' influence; } \\
\text { planning and organization; exhibition cost. }\end{array}$ \\
\hline Wang Hanxi (2012) & $\begin{array}{l}\text { economic benefit effect; display effect and relationship } \\
\text { cultivation effect, existing business and brand } \\
\text { promotion effect, new business development effect and } \\
\text { internal organization efficiency, public promotion effect } \\
\text { and industry information acquisition effect. }\end{array}$ \\
\hline Lei Chun (2018) & exhibition service indexes; exhibition scale indexes. \\
\hline Ling Li \& Wang Xiaomin (2016) & $\begin{array}{l}\text { core interest; basic service; brand and image; } \\
\text { core service. }\end{array}$ \\
\hline Wang Xiaomin (2017) & physical environment; professional service; core interest. \\
\hline Yang Fangping \& Yu Mingyang (2010) & $\begin{array}{l}\text { recognition and influence of the exhibition; } \\
\text { exhibition products; exhibition supporting service. }\end{array}$ \\
\hline Kim \& Lee (2010) & $\begin{array}{l}\text { consumer service; hardware facilities; instructions } \\
\text { and amenities; exhibition items; relevance; security; } \\
\text { public relations; exhibition cost. }\end{array}$ \\
\hline James M. Carman (1968) & $\begin{array}{l}\text { exhibition attractiveness; visitors' purchasing power; } \\
\text { potential customer groups and the traffic of exhibition } \\
\text { location; space cost; exhibition construction cost; } \\
\text { design cost; logistics transportation cost; labor cost. }\end{array}$ \\
\hline Cavanaugh (1976) & $\begin{array}{l}\text { numbers of visitors; visiting cost; transaction intention; } \\
\text { transaction intention cost. }\end{array}$ \\
\hline
\end{tabular}

*Through the above literature review.

and the other five participated in exhibitions many times before. The interview results showed that exhibitors of 2 enterprises clearly expressed their hope to improve their brand and market influence through the exhibition; of three enterprises proposed to pay attention to the exhibition scale; of two enterprises proposed to care about the exhibition visitors. Also, the exhibitor of one enterprise paid attention to the exhibition service and venue, and of one enterprise paid attention to whether the exhibition subject matched the needs of its own enterprise or not. In conclusion, the influential factors of evaluation exhibition concerned by enterprises are focused on the following five points:

1) Promoting the brands of exhibitors' enterprises and expanding the market;

2) Exhibition scales and visitors' quantity and quality;

3) Exhibition service;

4) Exhibition subject and enterprises' demands;

5) Exhibition service and venue. 


\subsection{Construction of Exhibition Evaluation Index System}

Based on the above research results, the exhibitor-based evaluation indexes are within four dimensions: exhibition brand and image, exhibition service, exhibition cost and exhibition revenue, with each dimension 8 to 10 evaluation indexes and a total of 35 evaluation indexes (can be seen at Table 2).

Table 2. Exhibition evaluation indexes.

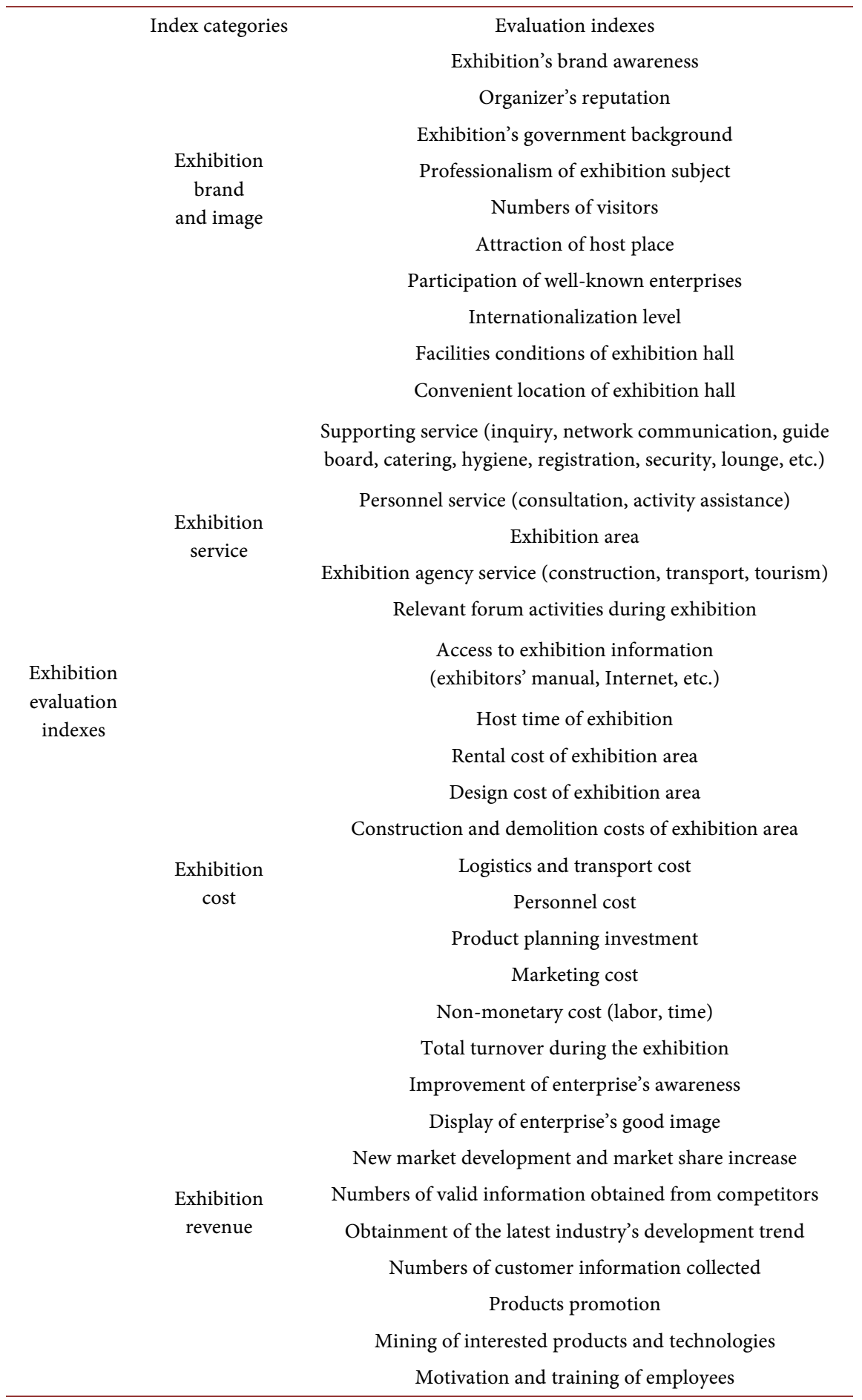




\subsection{Questionnaire Design and Pre-Survey}

The questionnaire design is mainly based on the information integrated from the previous literature review and analysis, interviews with exhibitors and enterprises, and expert opinions. At the same time, referring to the past experience of questionnaire design, the questionnaire design used for exhibitors to evaluate the exhibition is divided into two parts. 1) The basic information of the exhibitors' enterprises, including the times of exhibitors' participation, enterprise scales and positions of the respondents. 2) The importance evaluation of exhibition-related indexes with Likert five-score scale. Respondents need to evaluate the indexes from 1 - 5 points with the increased importance, of 1 point for very unimportant and 5 points for very important.

On December 27th, 2018, a pre-survey was conducted at Shenzhen Convention and Exhibition Center. A total of 40 questionnaires were distributed to exhibitors of "2018 China Educational Equipment \& Technology Show", of 40 collected and 37 valid. First, One-way ANOVA was used to test the significance level of the items, the results showed that all the 35 items were ${ }^{* *} \mathrm{P}<0.01$, indicating that the $\mathrm{t}$-test results of each analysis item were significant level, and all items could be reserved. Then, the Cronbach's a coefficient was used to test the internal consistency and stability of the scale, the results show that Cronbach's $\alpha$ coefficient of each dimension is greater than 0.8 , which shows that the scale has good stability and consistency, and the questionnaire design is reasonable.

\subsection{Research Results and Data Analysis}

The formal survey was conducted on exhibitors of "the 21st China Hi-Tech Fair in 2019" in the form of offline questionnaires. A total of 505 questionnaires were collected, of which 491 were valid, with a valid rate of $97.23 \%$. The collected data was analyzed by the SPSS software.

\section{Data analysis and System Construction}

\subsection{Data Analysis}

\subsubsection{Descriptive Analysis}

1) Samples' characteristics

The basic characteristic information of samples has been described from the times of exhibitors' participation, enterprise scales and positions of the respondents.

Times of exhibitors' participation. Among the 491 samples, of $27.3 \%$ participated in the exhibition for the first time, and of $72.7 \%$ participated in the exhibition more than 2 times, indicating that exhibitors being surveyed are experienced, and their assessment is more objective and reliable.

Enterprise scales. The results showed that the proportion of enterprises with a size of less than 50 people is $31.2 \%$, and those with a scale of 50 people, 100 people and 100 to 200 people are $21.4 \%, 14.9 \%$ and $32.6 \%$, respectively. Small and medium-sized exhibitors are the main groups in this survey. 
Positions of the respondents. The proportion of middle-level managers is $27.1 \%$, and that of first-line managers is $25.1 \%$, indicating that middle and first-line managers are main executives of enterprise exhibitors in this study, and their evaluation factors play an important role in this exhibition's quality evaluation (Table 3).

2) Factors description analysis

The mean values and standard deviation of four evaluation factors (exhibition brand and image, exhibition service, exhibition cost and exhibition revenue) were statistically analyzed. The results show as follows:

a) evaluation of the evaluation index system: the mean values of four major factors and the 35 items are all greater than 3.5, indicating that the evaluation index designed in the formal questionnaire is reasonable for exhibitors, with 35 index factors all influential factors of exhibitors' exhibition evaluation.

b) evaluation of four major factors: the mean value of exhibition brand and image (with 8 items) is 4.2675 , the mean value of exhibition service (with 9 items) is 3.8844 , the mean value of exhibition cost (with 8 items) is 3.77, and the mean value of exhibition revenue (with 10 items) is 4.165 . It indicates that the factors of "exhibition brand and image" and "exhibition revenue" have greater impacts on exhibition evaluation of exhibitors, and the other two factors of "exhibition service" and "exhibition cost" have relatively weaker impacts.

c) exhibition brand and image: the mean values of 8 factors are all more than 4.0, among which the mean values of "exhibition's brand awareness", "organizer's reputation", "professionalism of exhibition subject", "numbers of visitors" and "attraction of host place" are all more than 4.20, having greater impacts on exhibition brand and image. The mean values of the factors of "exhibition's government background", "participation of well-known enterprises' and "internationalization level" are among 4.00 and 4.16, having weaker impacts on the evaluation of exhibition brand and image of exhibitors.

Table 3. The descriptive statistical characteristics of the samples.

\begin{tabular}{cccc}
\hline characteristics & variable & numbers & percentage \\
\hline times of exhibitors' participation & 1 & 134 & $27.3 \%$ \\
& 2 & 86 & $17.5 \%$ \\
enterprise scales & 3 & 66 & $13.4 \%$ \\
& $>4$ & 205 & $41.8 \%$ \\
& -50 & 153 & $31.2 \%$ \\
Positions of the respondents & $100-200$ & 105 & $21.4 \%$ \\
& high-level managers & 73 & $14.9 \%$ \\
& middle-level managers & 133 & $32.6 \%$ \\
& first-line managers & 123 & $11.6 \%$ \\
\hline
\end{tabular}


d) exhibition service: the mean values of each factor are among 3.65 and 4.12, and the mean values of "convenient location" and "facilities conditions of exhibition hall" are 4.12, which are the two most important factors of exhibition service. The mean values of five factors, such as "host time of exhibition", "access to exhibition information", "personnel service", "exhibition area" and "supporting service facilities", are among 3.8 and 3.98, which are the second most important factors of exhibition service. The mean values of two factors of "exhibition agency service" and "relevant forum activities during exhibition" are 3.66 and 3.65 respectively, which are not important influential factors.

e) exhibition cost: the mean values of 8 factors are among 3.58 and 3.94, in which the mean values of three factors of "rental cost of exhibition area", "product planning investment" and "marketing cost" are greater than 3.90, which are important factors of exhibition cost.

f) exhibition revenue: the mean values of the 10 factors are among 3.72 and 4.44. Among them, the mean values of 8 factors, such as "improvement of enterprise's awareness", “display of enterprise's good image", "new market development and market share increase", "numbers of valid information obtained from competitors", "obtainment of the latest industry's development trend", "numbers of customer information collected", "products promotion" and "mining of interested products and technologies", are all greater than 4.0, which attracts more attention of exhibitors. The mean values of "total turnover during the exhibition" and "motivation and training of employees" are 3.72, which are not important factors of exhibition revenue. It indicates that exhibitors pay more attention to the long-term revenue of enterprise's influence, brand, awareness and future market share etc.

\subsubsection{Validity Analysis}

In the validity analysis, two principal components are extracted under the condition that the eigenvalue is greater than 1 , and are named according to the index characteristics (Table 4). The factors of exhibition brand and image are named as: component 1: exhibition image cognition factor; component 2: exhibition brand factor. The factors of exhibition service are named as: component 2: reachability factor; component 1: service perception factor. The factors of exhibition cost are named as: component 1: direct cost factor; component 2: indirect cost factor. There is only one principal component in the dimension of exhibition revenue, indicating that there is a strong correlation among these 10 factors. However, according to literature analysis and the author's subjective judgment, the factors of "B5: Numbers of valid information obtained from competitors"; "B6: Obtainment of the latest industry's development trend"; "B7: Numbers of customer information collected"; "B9: Mining of interested products and technologies" are not the same as other items. Therefore, six factors (B1 - B4, B8 and B10) are named as enterprise revenue factor and other four factors (B5 - B7, B9) are named as information search factor. 
Table 4. Exploratory factor analysis of influential factors.

\begin{tabular}{|c|c|c|c|c|c|c|}
\hline Dimensions & Components & Items & Results & Eigenvalues & $\begin{array}{c}\text { Variance } \\
\text { proportions }\end{array}$ & $\begin{array}{c}\text { Cumulative } \\
\text { variance } \\
\text { contribution } \\
\text { rates }\end{array}$ \\
\hline \multirow{7}{*}{$\begin{array}{l}\text { Exhibition } \\
\text { brand } \\
\text { and image }\end{array}$} & \multirow{6}{*}{1} & I4 Professionalism of exhibition subject & 0.653 & \multirow{5}{*}{3.688} & \multirow{5}{*}{46.098} & \multirow{5}{*}{46.098} \\
\hline & & I5 Numbers of visitors & 0.759 & & & \\
\hline & & I6 Attraction of host place & 0.714 & & & \\
\hline & & I7 Participation of well-known enterprises & 0.679 & & & \\
\hline & & I8 Internationalization level & 0.647 & & & \\
\hline & & I1 Exhibition's brand awareness & 0.659 & \multirow{3}{*}{1.005} & \multirow{3}{*}{12.565} & \multirow{3}{*}{58.663} \\
\hline & \multirow[t]{2}{*}{2} & I2 Organizer's reputation & 0.85 & & & \\
\hline \multirow{11}{*}{$\begin{array}{l}\text { Exhibition } \\
\text { service }\end{array}$} & & I3 Exhibition's government background & 0.802 & & & \\
\hline & \multirow{7}{*}{1} & S4 Personnel service & 0.438 & \multirow{6}{*}{1.204} & \multirow{6}{*}{13.378} & \multirow{6}{*}{57.58} \\
\hline & & S5 Exhibition area & 0.637 & & & \\
\hline & & S6 Exhibition agency service & 0.699 & & & \\
\hline & & S7 Relevant forum activities during exhibition & 0.813 & & & \\
\hline & & S8 Access to exhibition information & 0.758 & & & \\
\hline & & S9 Host time of exhibition & 0.564 & & & \\
\hline & & S1 Facilities conditions of exhibition hall & 0.721 & \multirow{3}{*}{3.978} & \multirow{3}{*}{44.202} & \multirow{3}{*}{44.202} \\
\hline & \multirow[t]{2}{*}{2} & S2 Convenient location of exhibition hall & 0.803 & & & \\
\hline & & S3 Supporting service facilities & 0.795 & & & \\
\hline & \multirow{5}{*}{1} & C1 Rental cost of exhibition area & 0.862 & \multirow{4}{*}{4.689} & \multirow{4}{*}{58.613} & \multirow{4}{*}{58.613} \\
\hline \multirow{6}{*}{$\begin{array}{l}\text { Exhibition } \\
\text { cost }\end{array}$} & & C2 Design cost of exhibition area & 0.866 & & & \\
\hline & & C3 Construction and demolition costs of exhibition area & 0.807 & & & \\
\hline & & C4 Logistics and transport cost & 0.642 & & & \\
\hline & & C5 Personnel cost & 0.569 & \multirow{4}{*}{1.037} & \multirow{4}{*}{12.966} & \multirow{4}{*}{71.579} \\
\hline & \multirow{3}{*}{2} & C6 Product planning investment & 0.85 & & & \\
\hline & & C7 Marketing cost & 0.833 & & & \\
\hline \multirow{11}{*}{$\begin{array}{l}\text { Exhibition } \\
\text { revenue }\end{array}$} & & C8 Non-monetary cost & 0.712 & & & \\
\hline & & B1 Total turnover during the exhibition & 0.478 & & & \\
\hline & & B2 Improvement of enterprise's awareness & 0.71 & & & \\
\hline & & B3 Display of enterprise's good image & 0.704 & & & \\
\hline & & B4 New market development and market share increase & 0.757 & & & \\
\hline & 1 & B5 Numbers of valid information obtained from competitors & 0.692 & 4631 & 16307 & 16207 \\
\hline & 1 & B6 Obtainment of the latest industry's development trend & 0.685 & 4.051 & 70.007 & 4.007 \\
\hline & & B7 Numbers of customer information collected & 0.729 & & & \\
\hline & & B8 Products promotion & 0.748 & & & \\
\hline & & B9 Mining of interested products and technologies & 0.686 & & & \\
\hline & & B10 Motivation and training of employees & 0.565 & & & \\
\hline
\end{tabular}




\subsubsection{One-Way ANOVA}

The one-way ANOVA is used to study the influence of exhibitors with different characteristics on exhibition evaluation. When the significance coefficient is less than 0.05 , there is a significant difference showing in related data. In this study, one-way ANOVA is used to analyze the 35 factors of four dimensions with the basic characteristic information: the times of exhibitors' participation, enterprise scales and positions of the respondents. The results show as follows.

1) Times of exhibitors' participation: $P$ values of each item are greater than 0.05 , indicating that the times of exhibitors' participation has no significant impact on exhibition evaluation.

2) Enterprise scales: among the 35 factors, only the factor of "organizer's reputation" has the $\mathrm{P}$ value of 0.031 , less than 0.05 , indicating that "organizer's reputation" has a different impact on enterprise scales.

3) Positions of the respondents: the P values of 4 factors (a total of 35) are less than 0.05 . These four factors are "numbers of visitors" (0.021); "attraction of host place" (0.044); "rental cost of exhibition area" (0.043) and "design cost of exhibition area" (0.018). In this study, the respondents are mainly middle and first-line managers, indicating that these four factors have significant impacts on the exhibition evaluation of middle and first-line managers, while not representing the impacts on the exhibition evaluation of senior managers.

Overall, the data analysis results show that the basic information of samples has a weak impact on evaluation factors. So, there is no more study of the correlation between them.

\subsection{The System Construction}

\subsubsection{Weight Calculation}

In calculating the weight, there are two methods of subjective assignment method and objective assignment method. In the subjective assignment method, people are taken as the core and the results are obtained by the subjective judgment of people's own experience lack of objectivity, but the results are more consistent with the expected judgment of the researchers and can better explain the data. In the objective assignment method, the calculated weights are relatively accurate, but the results may contradict the actual situation, which is difficult for researchers to explain. Referring to the results of the previous principal component analysis, each of the three dimensions of "exhibition brand and image", "exhibition service" and "exhibition cost" has two principal component factors. Although there is a slight gap of subjective judgment with relatively low cumulative variance rates obtained by principal component analysis, the values are within an acceptable range according to the actual situation and have few impacts on system construction. Therefore, principal component analysis is used to determine the factor weights in this study.

The weights of the extracted component factors are calculated, and the weighting degrees of the principal component factors under each dimension are obtained as follows: WI $(0.555,0.445)$, WS $(0.529,0.471)$, WC $(0.535,0.465)$. 
The results can be seen at Table 5 .

In this study, the weight coefficients of four dimensions are determined by factor analysis of 35 factors in the comprehensive layer. Seven common factors are extracted under the condition that the eigenvalue is greater than 1 . The factor loading matrix is obtained by the rotation of the maximum variance method. The results show that the weights of "exhibition brand and image", "exhibition service", "exhibition cost" and "exhibition revenue" are $0.227,0.277,0.277$ and 0.219 , respectively.

The importance ranking question for choosing the exhibition of "exhibition brand and image, exhibition service, exhibition cost and exhibition revenue" has been set up in the questionnaire in order to study the importance of the four dimensions of exhibitor-based evaluation. The ranking of four factors is calculated by the average comprehensive scores of each item, and the higher the score is, the higher the ranking is. The calculation method is as follows.

the average comprehensive scores of each item

$=(\Sigma$ frequency $*$ weight coefficient $) /$ number of total samples

In this study, the weight coefficient of the most important factor is " 4 ", and the others are " $3,2,1$ " in turn. The average comprehensive scores of each factor are as follows in Table 6.

The results are consistent with the previous analysis of four factors, that is, "the exhibition brand and image" and "exhibition revenue" are the influential factors which exhibitors pay more attention to.

\subsubsection{System Model Construction}

Based on the results of data analysis, factor weights, component factors and component factor weights, the exhibitor-based evaluation system model is constructed, as shown in Figure 1.

Table 5. Results of factor weights.

\begin{tabular}{cccc}
\hline Principal component factors & Components & Factors & Weights \\
\hline \multirow{2}{*}{ WI } & I1 & Exhibition image cognition factor & 0.555 \\
& I2 & Exhibition brand factor & 0.445 \\
WS & S1 & Reachability factor & 0.529 \\
& S2 & Service perception factor & 0.471 \\
WC & C1 & Direct cost factor & 0.535 \\
& C2 & Indirect cost factor & 0.465 \\
\hline
\end{tabular}

Table 6. Average comprehensive scores of four factors.

\begin{tabular}{cc}
\hline Factors & Average comprehensive scores \\
\hline Exhibition brand and image & 3.25 \\
Exhibition service & 1.85 \\
Exhibition cost & 2.05 \\
\hline
\end{tabular}




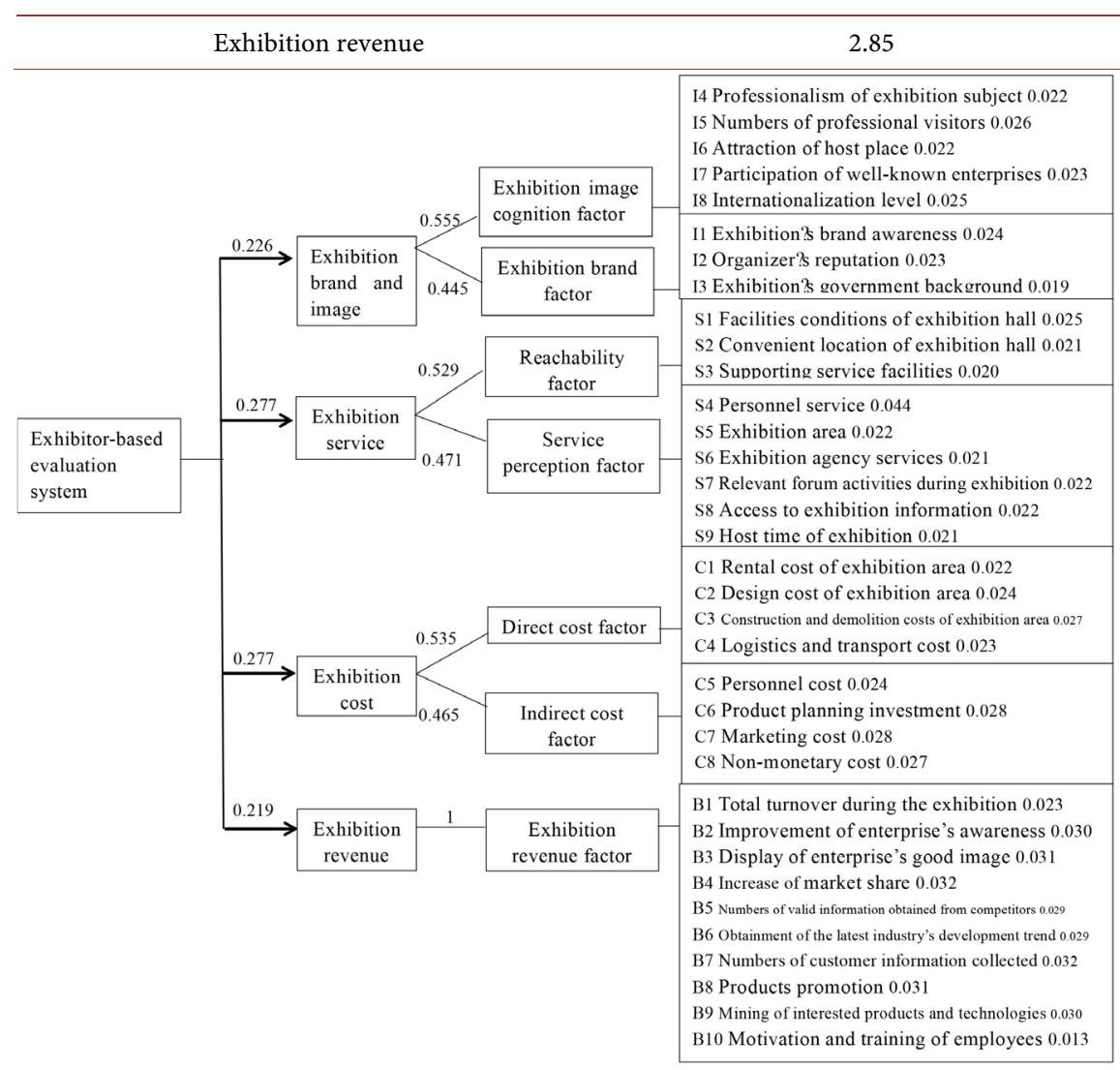

Figure 1. Exhibition evaluation system.

The weight coefficients of each factor and each dimension are clearly marked in Figure 1, from which the formula of exhibitor-based evaluation is shown as follows:

$$
I * 0.226+S * 0.277+C * 0.277+B * 0.219+e
$$

where " $e$ " representing for error.

\section{Conclusion}

Based on the literature review, expert interviews and interviews with senior practitioners, four main factors of exhibition evaluation for exhibitors are concluded of "exhibition brand and image", "exhibition service", "exhibition cost" and "exhibition revenue" with 35 sub-factors. The exhibitor-based evaluation system model is constructed. The results show that four main factors have different impacts on exhibition evaluation of exhibitors.

1) The two factors of "exhibition brand and image" and "exhibition revenue" have greater impacts on exhibition evaluation of exhibitors.

Exhibitors are particularly concerned about exhibition brand and image, which is related to the exhibitors' expectation of exhibition revenue. With regard to the expectation of exhibition revenue, exhibitors pay more attention to the long-term revenue of enterprises, such as long-term market influence, enterprise's awareness and brand promotion, related to exhibition brand and image. 
The more well-known and influential the exhibition is, the greater the long-term revenue will be for exhibitors. Therefore, the factor of "exhibition brand and image" has the greatest impact on exhibitors' decision-making and plays an important role in evaluating exhibition revenue. Therefore, exhibition revenue is not only the purpose of exhibitors, but also an important concern of exhibitors.

2) The two factors of exhibition service and exhibition cost have less impacts on exhibition evaluation of exhibitors.

The convenience of participating in the exhibition depends on exhibition service, and factors of exhibition service can be solved through consultation and communication, so exhibition service is not an important factor of exhibitor-based evaluation. Exhibition cost involves rental cost of exhibition area, design cost of exhibition area and logistics and transport cost etc. Compared with the expected exhibition revenue, exhibition cost is relatively few. Therefore, exhibition service and cost, enterprise's cost expenditure are not important factors of exhibitors' decision-making.

3) Both exhibition image cognition factor and exhibition brand factor have impacts on exhibitors' evaluation of exhibition brand and image.

Among them, five most important factors of exhibition brand and image are “exhibition's brand awareness", “organizer's reputation”, “professionalism of exhibition subject", "numbers of visitors" and "attraction of host place".

4) As for exhibition service factor, the reachability factor has the greatest impact on exhibition evaluation.

Among the reachability factor, two most important factors of exhibition service evaluation are "convenient location" and "facilities conditions of exhibition hall", while the not important factors involve "exhibition agency service" and "relevant forum activities during exhibition".

5) As for exhibition cost factor, the direct cost factor has a greater impact on exhibition evaluation of exhibitors, among which the three most significant factors are "rental cost of exhibition area", "product planning investment" and "marketing cost".

6) Among the exhibition revenue, there is a strong correlation within ten factors. Comparatively, exhibitors attach more importance to the following eight factors: "improvement of enterprise's awareness", "display of enterprise's good image", "new market development and market share increase", "numbers of valid information obtained from competitors", "obtainment of the latest industry's development trend", "numbers of customer information collected", "products promotion" and "mining of interested products and technologies". It shows that exhibitors pay more attention to the long-term revenue of enterprise's influence, brand, awareness and market share in the future.

7) The relevant factors of exhibitors' participation in the exhibition are "enterprise scales" and "positions of the respondents".

"The enterprise scales of exhibitors" has an impact on the exhibition expectations and their evaluation after the exhibition, mainly reflected in the factor of exhibition brand and image and might being an important factor of exhibitors' 
decision-making next time. Respondents with different positions reflect differently on the exhibition brand and image and exhibition cost, such as "numbers of visitors", "attraction of host place", "rental cost of exhibition area" and "design cost of exhibition area" and so on. In all, the basic information of samples has a weak impact on the exhibitor-based evaluation.

In conclusion, the influential factors of exhibitor-based evaluation are not only of difference but also of mutual influence. As for exhibition organizers, it's necessary to provide the good conditions and improve software and hardware facilities of the exhibition. Thus, the influential exhibition brand can be formed and the win-win situation with exhibitors can be achieved.

\section{Conflicts of Interest}

The authors declare no conflicts of interest regarding the publication of this paper.

\section{References}

Carman, J. M. (1968). Evaluation of Trade Show Exhibitions. California Management Review, 2, 35-44. https://doi.org/10.2307/41164157

Cavanaugh, S. (1976). Setting Objectives and Evaluating the Effectiveness of Trade Show Exhibits. The Journal of Marketing, 40, 100-103. https://doi.org/10.1177/002224297604000414

Godar, S. H., \& O’Connor, P. J. (2001). Same Time Next Year: Buyer Trade Show Motive. Industrial Marketing Management, 4, 77-86. https://doi.org/10.1016/S0019-8501(99)00100-5

Hansen, K. (2004). Measuring Performance at Trade Shows: Scale Development and Validation. Journal of Business Research, 57, 1-13. https://doi.org/10.1016/S0148-2963(02)00269-2

Kim, N. (2009). The Relation between Exhibitors' Show Performance and Service Quality of Trade Show: Research Base on International Trade Shows Held in Korea. http://files.Ibusdept.Com/uploads/IB Research_seminars/2007_2008/Namsu presentat ion paper.Pdf

Kim, N.-S., \& Lee, E. S. (2010). The Relationship between the Exhibitors' Show Performance and the Service Quality of Trade Shows. International Commerce and Information review, 12, 3-34.

Lei, C. (2018). An Analysis of Exhibition Evaluation Index from the Perspective of Stakeholders-Taking the Fourth China (Shenzhen) Tourism Expo as an Example. Economic Vision, 1, 30-35.

Li, L., \& Wang, X. M. (2016). A Study on Exhibitor's Exhibition Evaluation: Based on the Place Attachment Theory. Special Zone Economy, 2, 36-41.

Lu, S. Z. (2011). The Study on Exhibitors' Decision-Making of Trade Show Participation. M.A. Thesis, Beijing: Beijing International Studies University.

Wang, H. X. (2012). A Study on Performance Evaluation Model of Exhibitors. M.A. Thesis, Shanghai: East China Normal University.

Wang, X. M. (2017). Research on Classification and Integration of Exhibition Service Resources, and Exhibition Service Quality Evaluation: Based on Service-Dominant Logic. PhD Dissertation, Guangzhou: South China University of Technology. 
Wang, Y. A. (2018). Research on the Effect of Perceived Service Quality of Exhibitors on their Satisfaction and Behavioral Intension. M.A. Thesis, Tianjin: Tianjin University of Commerce.

Xu, Y. K. (2012). A Study on the Factors Influencing the Exhibition Selection Process of the Exhibitors. M.A. Thesis, Shanghai: East China Normal University.

Yang, F. P., \& Yu, M. Y. (2010). Research on Evaluation Index of Brand Exhibition Project Based on AHP. Modern Management Science, 4, 62-64. 